\title{
Conventional Dendritic Cell
}

National Cancer Institute

\section{Source}

National Cancer Institute. Conventional Dendritic Cell. NCI Thesaurus. Code C123782.

A subset of dendritic cells that are derived from myeloid precursors. They express toll-like receptors 2 and 4 and secrete interleukin-12. 